\title{
Characteristics of Lower Back Pain in Pregnant Ladies in Thiqar-Iraq
}

\author{
Ihsan Oudah Yasir ${ }^{1}$, Suaad Rodan Shoelef ${ }^{2}$ \\ Specialist Orthopedic and Trauma Surgeon, National Board F.I.B.M.S Orth., Alhusein teaching hospital - Thiqar, \\ Iraq, ${ }^{2}$ Specialist obstetrics and Gynecology, national board F.I.B.M.S Gyn\&Obs., Bint Alhuda Teaching Hospital \\ Thiqar, Iraq
}

\begin{abstract}
Objectives: to evaluate the frequency of back pain among pregnant female in Thiqar province in Iraq and its demographic characteristics.

Methodology: this is a case series descriptive study of one hundred pregnant female in Thiqar province in Iraq complaining from lower back pain in different stages of their pregnancies. the patients were evaluated firstly by history taking through questioner specially prepared for this study ;as well as; clinical and radiological assessment.

Results: in our study seventy one patients experience back pain in different stages of pregnancy giving a (71\%) as frequency of back pain in the studded group. Most of the patients Seventy four patients (74\%) developed the pain during the first trimester of pregnancy and ( $22 \%$ ) experience the pain during the second trimester. Fifty eight (14) patients (11.96\%) gave history of previous back problems before pregnancy; of these; nine patients $(7.69 \%)$ diagnosed before pregnancy as herniated lumbar disc prolapse and kept on medical treatment and physiotherapy, 2 patients $(1.7 \%)$ with previous laminectomy surgeries for herniated lumbar disc prolapse, 3 patients (2.56) with diagnosis of degerative spine. One patient underwent cesarean section for sever back pain dueto lumbar disc prolapse at the end of the pregnancy period ( non-gynecological indication for cesarean section ).
\end{abstract}

Conclusion: lower back pain is a common problem during pregnancy , and it shows some common epidemiological characteristics.

Keywords: Thiqar-Iraq ; back pain ; pregnant ladies

\section{Introduction}

Low back pain is a common complaint among pregnant women. It is estimated that about $50 \%$ of pregnant women complain of some form of back pain at some point in pregnancy or during the postpartum period (1).

Pregnancy has a profound effect on the human body, particularly the musculoskeletal system. Hormonal changes cause ligamentous joint laxity, weight gain, and a shift in the center of gravity that leads to lumbar spine hyperlordosis and anterior tilting of the pelvis. In addition, vascular changes may lead to compromised metabolic supply in the low back. The most common musculoskeletal complaints in pregnancy are low back pain and/or pelvic girdle pain. They can be diagnosed and differentiated from each other by history taking, clinical examination, provocative test maneuvers, and imaging. Management ranges from conservative and pharmacologic measures to surgical treatment. Depending on the situation, and given the unique challenges pregnancy places on the human body and the special consideration that must be given to the fetus, an orthopedic surgeon and the obstetrician may have to develop a plan of care together regarding labor and delivery or when surgical interventions are indicated ${ }^{(2)}$.

Risk factors that contribute to the development of low-back pain during pregnancy have been examined in several studies. The results consistently suggest that the major predictors of back pain during pregnancy are back 
pain prior to pregnancy and multiparity. [ Age, height, weight, race, baby weight, and socioeconomic status do not seem to correlate with risk for development of back pain during pregnancy ${ }^{(3)}$.

Two major subtypes of back pain occurs during pregnancy ; (Lumbar and pelvic pain) lumbar pain located at and above the waist in the center of the back. But what is most common is the posterior pelvic pain which 5 times more common than lumbar pain and experience below the west on either sides ${ }^{(4)}$.

Usually the treatment is conservative by rest, sleeping on the side, physiotherapy, lifting in proper way without bending, acetaminophen may be sufficient to relieve the pain. But ; the managing doctor should remember the fact that Bach pain during pregnancy may be a sign of premature labor or urinary tract infection. Sever back pain during pregnancy lasting more than one week is dangerous sign and need physician consultation (5).

\section{Patients, material and method}

This is case series of One hundred pregnant in Thiqar province in the south of Iraq were studied, all patients were selected randomly from the outpatients clinic of Bint Alhuda teaching hospital during their antenatal care visits and history of back pain were recorded; patients with positive history of lower back pain were evaluated by gynecologist firstly to exclude non-musculoskeletal back pain like preterm labor, urinary tract infection or other rare cause like ectopic pregnancy, such patients were excluded from the study, all patients then were referred to orthopedic out patient in Alhusein teaching hospital and evaluation done by orthopedic surgeon by history taking according to special questioner .clinical musculoskeletal examination of the back done by localizing the site of the pain, straight leg rising test, FABER test for sacroiliac joint pathology, in addition to full neurological examination of the lower limbs. Some patient were sent to $\mathrm{x}$-ray examination for lumbosacral spine and the data from the were collected aiming to study the demographic and epidemiological characteristic of back pain problem in Thiqar province-Iraq.

\section{Results}

Our study include 100 pregnant women. 71 patients were found to have back pain giving frequency of $(71 \%)$ .The mean age of the pregnant woman was 29.4 years. The mean gestational age were 28.3 week . 29 patients
( $41 \%$ ) were employer. Thirty nine patients out of 71 patients with back pain (54.92\%) were not completed their secondary school. Fifty four patient out of 71 were multipara (76.05) . seventeen patients out of 71 with back pain patient ere primigravida( 23.94) .forty one patients of multipara patients experience the same back pain during previous pregnancy( 75.92). fifty seven patient out of 71 patient with back pain experienced the pain during second trimester $(80.28 \%)$. The pain nature was burning sensation in lower back in 49 patients (69.01\%). thirty patients with back pain have striae gravidarum in the lower abdomen and flanks ( $42.25 \%$ ).

\section{Discussion}

Some studies considered back pain during pregnancy is a part of the pregnancy reflecting its common occurrence, $\mathrm{Ng} \mathrm{BK}$ and his colleagues studied the frequency of back pain during pregnancy and it shows a frequency of $84.6 \%$; our result is consistent with that study in which a result of $71 \%$ indicating that this problem is common during pregnancy in addition to; this study is the one of the few studies which discussed the strong association between the problem of back pain during pregnancy in office worker, our study also shows some association between employment of pregnant female and the problem of back pain $(41 \%)^{(6)}$.

In our study $54.92 \%$ of pregnant female with back pain didn't completed their secondary education and this result is significantly differs from that of Carvalho MECC in his study which showed only $16.8 \%$ only and this difference may be dueto the cultural and educational facilities between our country and European population $^{(1)}$.

Our study show association between multiparity, striae gravidarum and the problem of back pain and this association is well studied by Kokanalı D which showed a an association between presence and severity of striae gravidarum and back pain ${ }^{(7)}$.

Our study shows that most of pregnant female developed the back pain during second trimester of pregnancy $(81.4 \%)$ and this finding is not consistent with result of Carvalho MECC in his study who show incidence of back pain during second trimester is only $43.7 \%$ a point which need further study and evaluation (1).

Ethical Clearance: The Research Ethical Committee at scientific research by ethical approval of 
both environmental and health and higher education and scientific research ministries in Iraq

Conflict of Interest: The authors declare that they have no conflict of interest.

Funding: Self-funding

\section{References}

1. Carvalho MECC; Lima LC; de Lira Terceiro CA; Pinto DRL; Silva MN; Cozer GA; Couceiro TCM. 2017. Low back pain during pregnancy. Rev Bras Anestesiol. 2017; 67(3):266-270.

2. Casagrande, Danielle MD; Gugala, Zbigniew MD, PhD; Clark, Shannon M. MD; Lindsey, Ronald W. MD. 2015. Low Back Pain and Pelvic Girdle Pain in Pregnancy. JAAOS - Journal of the American Academy of Orthopaedic Surgeons: September 2015 - Volume 23 - Issue 9 - p 539-549.

3. Medscape General Medicine; Managing Back
Pain During Pregnancy. 2015;1(2). https://www. medscape.com/viewarticle/719230_2.

4. Stephen P. Montgomery, MD. 2019. Types of Back Pain in Pregnancy. https://www.spine-health.com/ conditions/pregnancy-and-back-pain/types-back-painpregnancy.

5. Mayo Clinic Staff. April 09, 2019. Pregnancy week by week. https://www.mayoclinic.org/healthylifestyle/pregnancy-week-by-week/in-depth/ pregnancy/art-20046080.

6. Ng BK; Kipli M; Abdul Karim AK; Shohaimi S; Abdul Ghani NA; Lim PS.2017. Back pain in pregnancy among office workers: risk factors and its impact on quality of life. Horm Mol Biol Clin Investig. 2017; 32(3) (ISSN: 1868-1891).

7. Kokanalı D; Çağlar AT.2018. Hidden association between the presence and severity of striae gravidarum and low back pain in pregnancy. Eur J Obstet Gynecol Reprod Biol. 2018; 233:4952 (ISSN: 1872-7654) 